\title{
Viral Stimuli Trigger Exaggerated Thymic Stromal Lymphopoietin Expression by Chronic Obstructive Pulmonary Disease Epithelium: Role of Endosomal TLR3 and Cytosolic RIG-I-Like Helicases
}

\author{
Jenny Calvén ${ }^{\mathrm{a}}$ Yulyana Yudina ${ }^{\mathrm{a}} \quad$ Oskar Hallgren $^{\mathrm{b}}$ \\ Gunilla Westergren-Thorsson ${ }^{b}$ Donna E. Davies ${ }^{c}$ Angelica Brandelius ${ }^{a}$ \\ Lena Uller ${ }^{\mathrm{a}}$ \\ Units of a Respiratory Immunopharmacology and ${ }^{\mathrm{b}}$ Lung Biology, Lund University Sweden, Lund, Sweden; \\ 'The Brooke Laboratories, Division of Infection, Inflammation and Immunity, School of Medicine, University of \\ Southampton, Southampton, UK
}

\section{Key Words}

Chronic obstructive pulmonary disease $\cdot$ Rhinovirus •

Thymic stromal lymphopoietin · TLR3

\begin{abstract}
Background: Rhinovirus (RV)-induced chronic obstructive pulmonary disease (COPD) exacerbations exhibit $\mathrm{TH}_{2}$-like inflammation. We hypothesized that RV-infected bronchial epithelial cells (BEC) overproduce $\mathrm{TH}_{2}$-switching hub cytokine, thymic stromal lymphopoietin (TSLP) in COPD. Methods: Primary BEC from healthy (HBEC) and from COPD donors (COPD-BEC) were grown in 12-well plates, infected with RV16 (0.5-5 MOI) or stimulated with agonists for either tolllike receptor (TLR) 3 (dsRNA, 0.1-10 $\mu \mathrm{g} / \mathrm{ml}$ ) or RIG-I-like helicases (dsRNA-LyoVec, $0.1-10 \mu \mathrm{g} / \mathrm{ml}$ ). Cytokine mRNA and protein were determined (RTqPCR; ELISA). Results: dsRNA dose-dependently evoked cytokine gene overproduction of TSLP, CXCL8 and TNF- $\alpha$ in COPD-BEC compared to HBEC. This was confirmed using RV16 infection. IFN- $\beta$ induction did not differ between COPD-BEC and HBEC. Endosomal TLR3 inhibition by chloroquine dose-dependently inhibited dsRNA-induced TSLP generation and reduced generation of CXCL8, TNF- $\alpha$, and IFN- $\beta$. Stimulation of cytosolic viral sen-
\end{abstract}

sors (RIG-I-like helicases) with dsRNA-LyoVec increased production of CXCL8, TNF- $\alpha$, and IFN- $\beta$, but not TSLP. Conclusions: Endosomal TLR3-stimulation, by dsRNA or RV16, induces overproduction of TSLP in COPD-BEC. dsRNA- and RV-induced overproduction of TNF- $\alpha$ and CXCL8 involves endosomal TLR3 and cytosolic RIG-I-like helicases and so does the generation of IFN- $\beta$ in COPD-BEC. RV16 and dsRNAinduced epithelial TSLP may contribute to pathogenic effects at exacerbations and development of COPD.

Copyright @ 2011 S. Karger AG, Basel

\section{Introduction}

Despite the available drug treatments, exacerbations of chronic obstructive pulmonary disease (COPD) cause significant morbidity and mortality. Hence, this is an area with significant unmet medical need. Rhinovirus (RV) infection has been identified as a main trigger associated with exacerbations of both asthma and COPD $[1,2]$. RV is known as a pathogen of the upper airways. However, it is now established that RV also infects the bronchial epithelium [3, 4]. Epithelial responses evoked by exposure to RV include the generation of proinflam-

\section{KARGER \\ Fax +41613061234 \\ E-Mail karger@karger.ch}

www.karger.com
(C) 2011 S. Karger AG, Basel

1662-811X/12/0041-0086\$38.00/0

Accessible online at:

www.karger.com/jin
Dr. Lena Uller

Unit of Respiratory Immunopharmacology

BMC D12, Lund University

SE-22184 Lund (Sweden)

Tel. +46 46222 0413, E-Mail Lena.Uller@ med.lu.se 
matory cytokines and antiviral INF- $\beta$ [5]. Epitheliumderived thymic stromal lymphopoietin (TSLP) is an upstream cytokine with potentially important roles in the pathogeneses of allergic and inflammatory airways diseases [6-8]. TSLP presents a structural and functional homology to IL-7, and its receptor (TSLPR) is a heterodimer consisting of a specific TSLPR and the IL-7 receptor $\alpha$-chain [7]. TSLPR is expressed by myeloid dendritic cells, monocytes, pre-activated T cells, NK cells, and mast cells [7]. Epithelial cells produce TSLP in response to toll-like receptor (TLR)-3 signaling and through the action of cytokines including TNF- $\alpha[7,9]$. Through its actions on mast cells, T lymphocytes, and dendritic cells, TSLP links innate and adaptive immune responses $[6,7]$. TSLP may directly expand subsets of T lymphocytes, but a major action seems to be activation of dendritic cells. Overexpression of TSLP in mouse lungs induces progressive pulmonary inflammation characteristic of mouse asthma models [8]. We speculated that RV, through epithelial TLR3 stimulation, might induce production of TSLP in exacerbations of COPD, and thus contribute to the development of this disease.

Double-stranded RNA (dsRNA) is produced during $\mathrm{RV}$ replication and causes innate immune responses including epithelial generation of interferons and inflammatory cytokines $[10,11]$. We have previously demonstrated that primary epithelial cells cultured from bronchial brushings from asthmatic donors overproduce TSLP in response to dsRNA compared with a group of healthy control subjects [11]. Supporting its utility as a viral surrogate stimulus, synthetic dsRNA (polyinosinepolycytidylic acid; poly I:C) mimics several aspects of RV infection in human bronchial epithelial cells (BEC), including the generation of a range of cytokines and interferons [11, 12]. Additionally, the effects of dsRNA may reveal pathogenic actions of TLR3-stimulating RNA emanating from dying cells, independent of viral infection [13]. This is of interest since necrotic cell debris may occur to a significant extent in the airways in severe asthma and COPD. Asthma has many features of an eosinophilic $\mathrm{TH}_{2}$-type disease. Indeed, this has been a basis for attributing a major role to TSLP in asthma $[6,7]$. In contrast, COPD has traditionally been regarded a neutrophilic $\mathrm{TH}_{1}$ type disease. A role for TSLP in COPD has accordingly received little attention by comparison with the major focus on TSLP as a 'master switch' in asthma $[6,8]$. However, it has recently been reported that $\mathrm{TH}_{2}$ features actually characterize COPD exacerbations. These features include airway eosinophilia [2], increased occurrence of $\mathrm{TH}_{2}$ type $\mathrm{CD} 8+\mathrm{T}$ cells (Tc2 cells) in par-
Table 1. Study subjects and characteristics

\begin{tabular}{lcc}
\hline & Controls & COPD \\
\hline $\mathrm{n}$ & 7 & 8 \\
Age, years & $58(56-62)$ & $62(53-66)$ \\
Pack years & $20(15-40)$ & $41(25-60)$ \\
Gender (M/F), & $40 / 60$ & $37 / 63$ \\
Lung function & & \\
$\quad$ FEV & & $0.57(0.4-0.9)$ \\
$\quad$ FEV $_{1} \%$ predicted & - & $19.7(14-24)$ \\
$\quad$ FVC & - & $2.0(1.3-2.8)$ \\
$\quad$ FEV $_{1} \%$ predicted/FVC & - & $31(20-39)$ \\
\hline
\end{tabular}

Ranges are given in parentheses. $\mathrm{FEV}_{1}=$ Forced expiratory volume in $1 \mathrm{~s} ; \mathrm{FVC}=$ vital capacity $\mathrm{FEV}_{1} ; \%$ predicted $=$ forced expiratory volume in $1 \mathrm{~s}$ expressed as a percentage of the predicted value.

ticular [14-17], and high levels of IL-4 in the airways [18]. These data support our hypothesis that TSLP could be involved in COPD exacerbations.

Exacerbations are more frequent and severe in patients with already established severe COPD [19]. Hence, we considered that BEC obtained from individuals suffering from such severe COPD as would make them eligible for lung transplant may respond to RV infection with overproduction of TSLP. In this study, involving RV16 as well as dsRNA-exposed epithelial cells obtained from healthy and diseased bronchi, we have examined effects on gene expression and generation of TSLP protein. In addition, we have examined effects on TNF- $\alpha$ and CXCL8, two central cytokines in COPD [20] both of which are increased in the airways at exacerbations [21]. A further comparison is made with viral-stimulation-induced effects on epithelial expression of a major antiviral interferon, IFN- $\beta$. By the use of additional stimulatory and inhibitory tools, we have also explored involvement of endosomal (TLR3) versus cytosolic pathogen recognition receptors (RIG-I-like helicases) in the present viral-stimulus-induced cytokine production.

\section{Material and Methods}

BEC from COPD (GOLD Stage IV) and Healthy Controls

Primary cultures of human BEC were established from explanted lungs recovered from COPD patients diagnosed with smoke-induced GOLD stage IV $(n=8$; table 1$)$ and selected for lung transplantation at Lund University Hospital. Explanted lungs were handled immediately (within $30 \mathrm{~min}$ after surgery) and $\mathrm{BEC}$ were purified from the lungs by protease digestion of 
main bronchi, and cells were grown in serum-free hormonally supplemented bronchial epithelium growth medium (Clonetics, San Diego, Calif., USA) in $37^{\circ} \mathrm{C}$ and $5 \% \mathrm{CO}_{2}$ as previously described [11]. Primary cultures of healthy BEC (HBECs) from the healthy-donor previous-smoker age-matched control group $(\mathrm{n}=$ 7; table 1) were purchased from Lonza (Walkersville, Md., USA) as cryopreserved cells. Initial experiments were also performed with HBECs from healthy non-smoking donors $(n=3)$ purchased from Lonza as cryopreserved cells. Informed consent was obtained from all COPD study participants. The study was approved by the Swedish Research Ethical Committee in Lund, Sweden (FEK 91/2006).

\section{Stimulation of Cells with dsRNA for TLR3 Activation and} dsRNA-LyoVec for RIG-I/MDA5 RNA Helicase Activation

All experiments were performed with cells in passage 2-3. BEC were seeded into collagen-coated 12-well plates (Nunc; Life Technologies, Carlsbad, Calif., USA) as previously described [11], and when $80-90 \%$ confluent, the growth medium was replaced with bronchial epithelial basal medium (Clonetics, San Diego, Calif., USA) containing insulin $(5 \mu \mathrm{g} / \mathrm{ml})$, transferrin (5 $\mu \mathrm{g} / \mathrm{ml})$, and sodium selenite (5 $\mathrm{ng} / \mathrm{ml}$; ITS, Sigma, Poole, UK) and $0.1 \%$ BSA, and cells were rendered quiescent for $24 \mathrm{~h}$ before the start of the experiment. Cells were stimulated with a synthetic dsRNA analogue, the TLR3 agonist (poly I:C; InvivoGen, San Diego, Calif., USA), and were tested in the range of $0.1-10$ $\mu \mathrm{g} / \mathrm{ml}$ to establish dose-dependent effects as previously described [11]. Similarly, cells were stimulated with dsRNA-LyoVec $(0.1$ and $1 \mu \mathrm{g} / \mathrm{ml})$ which activates the RIG-I-like helicases RIGI/MDA5 (dsRNA/LyoVec, InvivoGen) [22]. Cell morphology was monitored thoroughly during each experiment using light microscopy, and cell counts using trypan blue staining were performed in initial experiments to exclude any effects of the treatments on cell death.

\section{Inhibition of TLR3 Signaling}

Chloroquine (Sigma-Aldrich, Gillingham, UK), an inhibitor of endosomal acidification [23] and TLR3-signalling, was dissolved in cell culture medium and added to the cells in different concentrations $1 \mathrm{~h}$ prior to stimulation with $1 \mu \mathrm{g} / \mathrm{ml}$ dsRNA, as previously described [11]. HBEC and COPD-BEC were stimulated with dsRNA for either 3 or $24 \mathrm{~h}$ in the presence of chloroquine. Cell supernatant was removed for protein analysis and the cells lysed and harvested for mRNA analysis as described below.

\section{Cytokine Measurement by ELISA}

Release of cytokines, TSLP, CXCL8, TNF- $\alpha$ (R\&D Systems, Abingdon, UK) and IFN- $\beta$ (PBL Biosource, Calif., USA) into culture supernatants of BEC were measured after $24 \mathrm{~h}$ stimulation with dsRNA, RV16, or RIG-I like helicases using ELISA assay kits according to the manufacturer's instructions.

\section{Infection with RV16}

In separate experiments, COPD-BEC and HBEC were infected with RV16 grown in Ohio HeLa cells (European Collection of Cell Cultures) or treated with cell culture medium only or UV-inactivated virus as control as previously described [5]. UV-inactivation was performed using a UV-crosslinker (UPV, Cambridge, UK) irradiating the virus for $50 \mathrm{~min}$ using $120,000 \mu \mathrm{J} / \mathrm{cm}^{2} \mathrm{UV}$ light as previously described [5]. Epithelial cells were infected with RV16 at different levels of multiplicity of infection (MOI), 0.1-5 MOI for $1 \mathrm{~h}$ at room temperature with shaking. UV-inactivated virus was diluted similarly to the dose of 5 MOI. Virus preparations were removed, washed 3 times with $1 \mathrm{ml}$ PBS, and $1 \mathrm{ml}$ fresh medium bronchial epithelial basal medium was added, and the cells were incubated in $37^{\circ} \mathrm{C}$ and $5 \% \mathrm{CO}_{2}$ for $24 \mathrm{~h}$.

RNA Extraction and Quantification of TSLP, TNF- $\alpha, C X C L$, and IFN- $\beta$ Gene Expression with RT- $q P C R$

Total RNA was extracted from primary BEC using a RNA extraction kit NucleospinT RNA II (Machery-Nagel, Düren, Germany), according to manufacturer's instructions. Total RNA $(1 \mu \mathrm{g})$ was reverse transcribed to cDNA using an RT-kit (Primerdesign, Southampton, UK) and qPCR was performed as previously described $[11,24]$. Briefly, thermocycling and real-time detection of PCR products were performed on an IcyclerIQ sequence detection system (Stratagene, Mx3000P, La Jolla, Calif., USA) with standard cycling parameters. Genes of interest were normalized to the geometric means of housekeeping genes Ubiquitin $\mathrm{C}$ and GAPDH using the $\Delta \mathrm{C}_{\mathrm{t}}$ method. Within-group comparisons were normalized to one control sample of a single patient using the $\Delta \Delta \mathrm{C}_{\mathrm{t}}$ method. Between-groups comparisons were only conducted where conditions were the same and normalized to the value of a control sample of a single healthy patient by the $\Delta \Delta \mathrm{C}_{\mathrm{t}}$ method. The following primer sequences were used for TSLP, TNF- $\alpha$, CXCL8, and IFN- $\beta$. TSLP: AATCCAGAGCCTAACCTTCAATC (forward) and GTAGCATTTATCTGAGTTTCCGAATA (reverse). TNF- $\alpha$ : AGGTTCTCTTCCTCTCACATAC (forward) and ATCATGCTTTCAGTGCTCATG (reverse). CXCL8: CAGAGACAGCAGAGCACAC (forward) and AGCTTGGAAGTCATGTTTACAC (reverse). IFN- $\beta$ : TTACTTCATTAACAGACTTACAGGT (forward) and TACATTAGCCATCAGTCACTTAAAC (reverse).

\section{Statistical Analysis}

Statistical analysis was performed using the software GraphPad Prism version 5.0 (GraphPad Software, San Diego, Calif., USA). Data were expressed as median values with interquartile ranges and were analyzed using non-parametric tests. Data within each group (COPD and healthy) were analyzed using Friedman's one-way ANOVA and the Kruskal-Wallis test. Statistical differences between COPD and healthy groups were determined using the Mann-Whitney $U$ test. Values of $\mathrm{p}<0.05$ were considered statistically significant.

\section{Results}

\section{dsRNA Evokes Overproduction of TSLP, TNF- $\alpha$, and CXCL8 in COPD-BEC}

dsRNA in the form of synthetic poly (I:C) as used in this study has been demonstrated to activate TLR3 receptors in BEC from healthy and asthmatic subjects [11]. TSLP, TNF- $\alpha$, and CXCL8/IL-8 mRNAs were dose dependently $(\mathrm{p}<0.05)$ increased $3 \mathrm{~h}$ after adding dsRNA in both HBEC and COPD-BEC (fig. 1). Induction of TSLP gene expression was markedly greater in COPD-BEC 


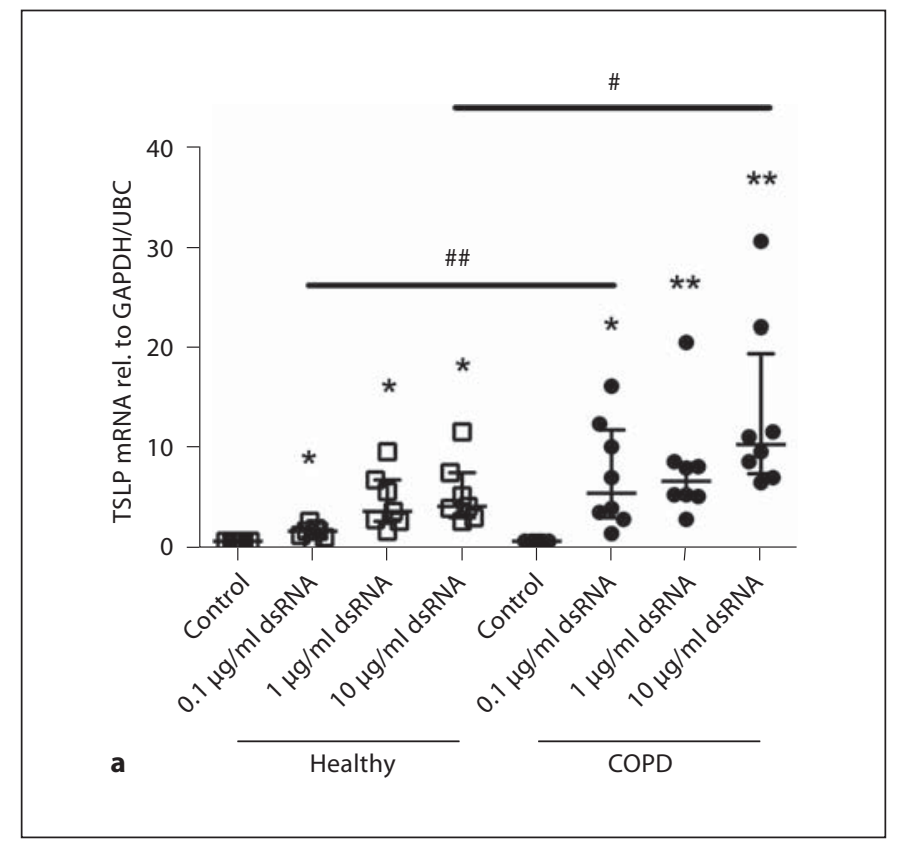

Fig. 1. Effects of dsRNA on cytokine gene expression of TSLP (a), TNF- $\alpha(\mathbf{b})$, and CXCL8 (c) in BEC from donors with severe COPD $(\mathrm{n}=8)$ and from healthy individuals $(\mathrm{n}=6)$. TSLP mRNA was markedly overexpressed in response to dsRNA stimuli at $3 \mathrm{~h}$ in the severe COPD group compared to healthy controls (a). At this time point, TNF- $\alpha$ mRNA (b) as well as CXCL8/IL-8 mRNA (c) were dose-dependently induced similarly in the healthy and COPD groups. Each point corresponds to a single individual, and data are expressed as medians with IQR. ${ }^{*} \mathrm{p}<0.05,{ }^{* *} \mathrm{p}<0.01$ dsRNA effects vs. control; ${ }^{\#} \mathrm{p}<0.05,{ }^{\# \#} \mathrm{p}<0.01$ healthy vs. COPD.

than in HBEC (fig. 1a). dsRNA-induced TSLP expression and protein release did not differ between healthy nonsmokers and healthy smokers (online suppl. fig. 1, see www.karger.com/doi/10.1159/000329131). dsRNA dosedependently increased release of TSLP, TNF- $\alpha$, and CXCL8 (fig. 2), although in the case of TSLP this effect was marked only in COPD-BEC (fig. 2a). The dsRNAinduced production of CXCL8 and TNF- $\alpha$ was also
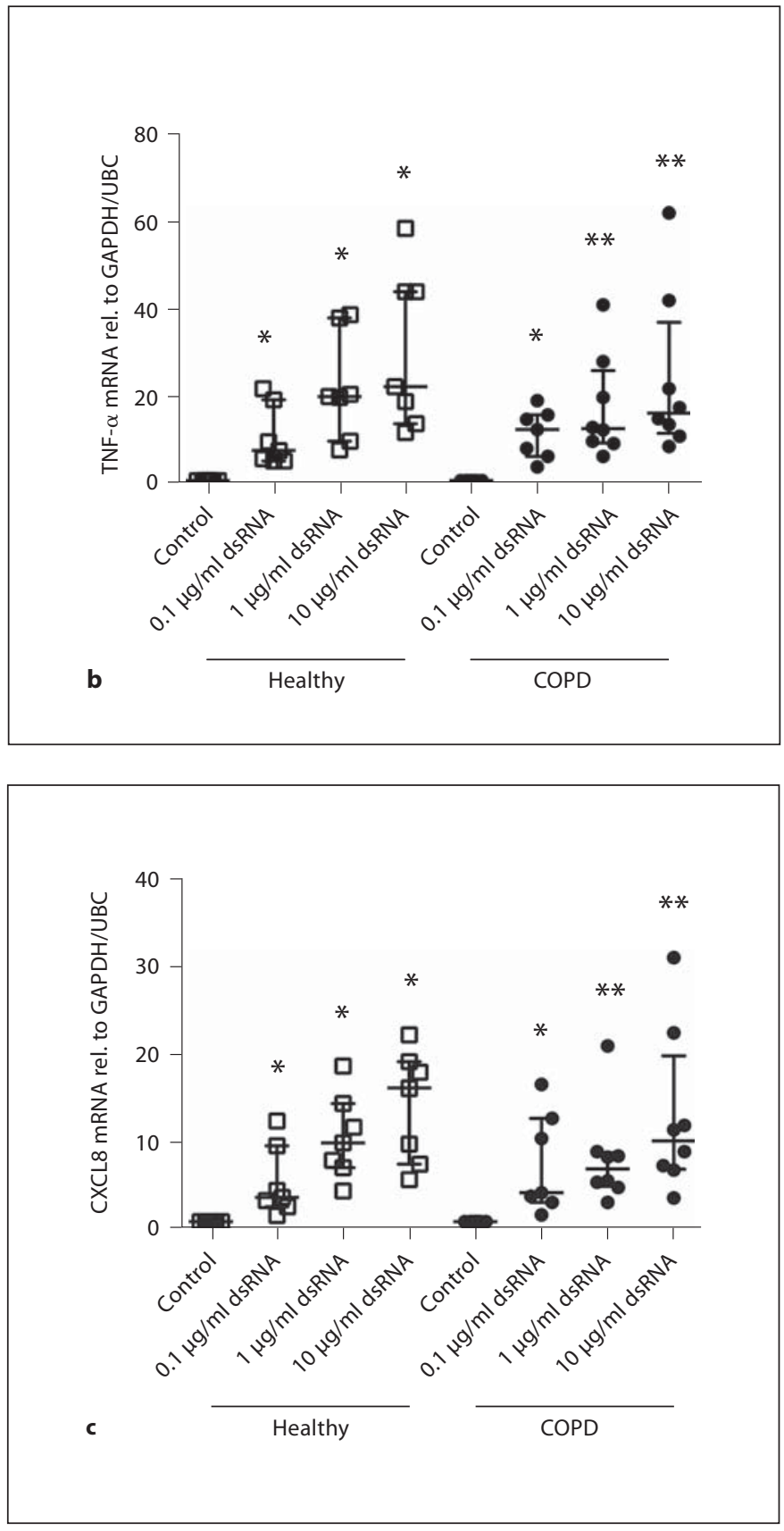

markedly greater in COPD-BEC compared to HBEC (fig. 2b, c). Generally the dose response to dsRNA revealed a consistent and marked but still sub-maximal response at $1 \mu \mathrm{g} / \mathrm{ml}$. Hence, subsequent experiments involving different interactions were carried out using a concentration of $1 \mu \mathrm{g} / \mathrm{ml}$ dsRNA. The baseline release of TSLP, TNF- $\alpha$, and CXCL8 proteins did not differ between HBEC and COPD-BEC (fig. 2). 

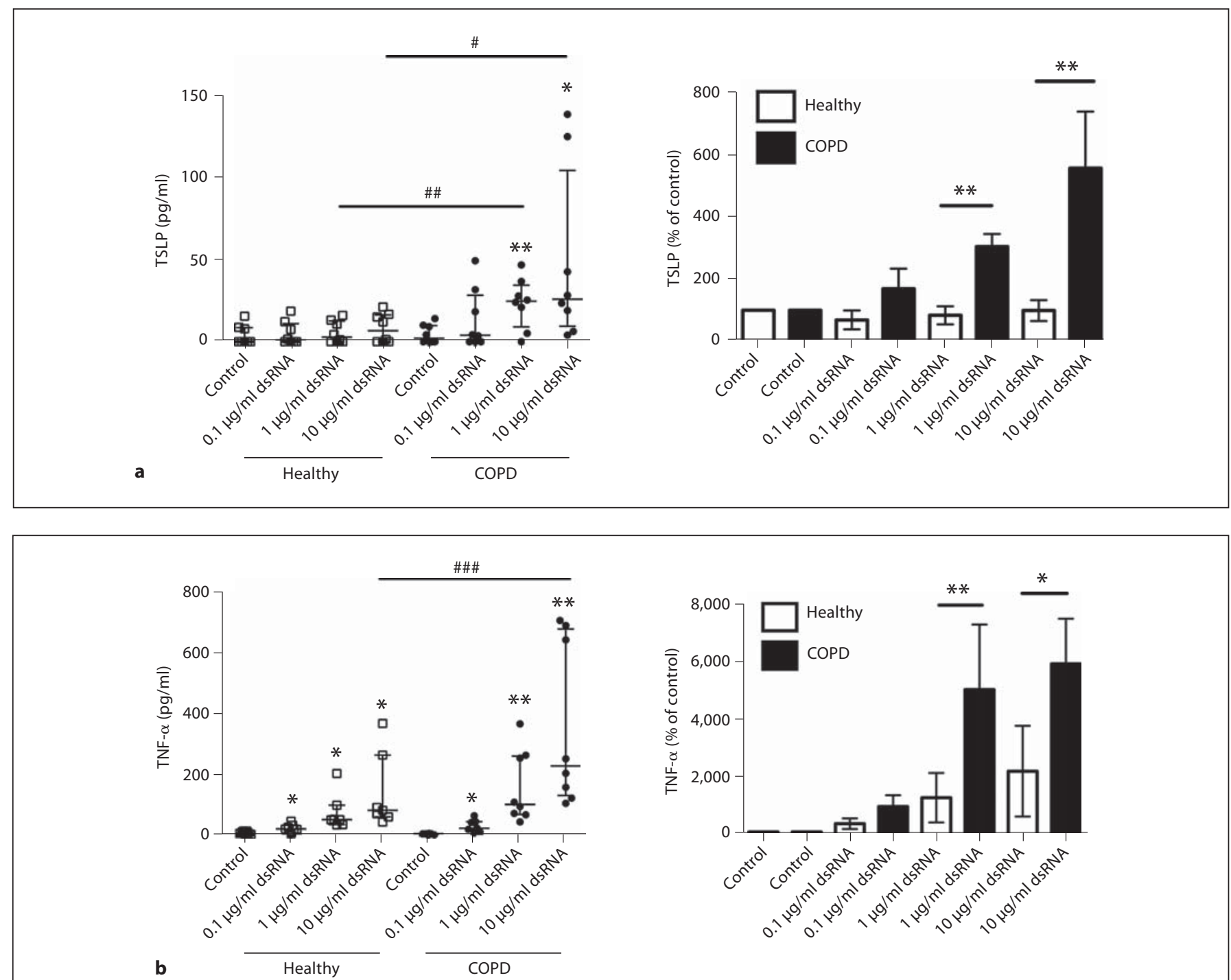

b

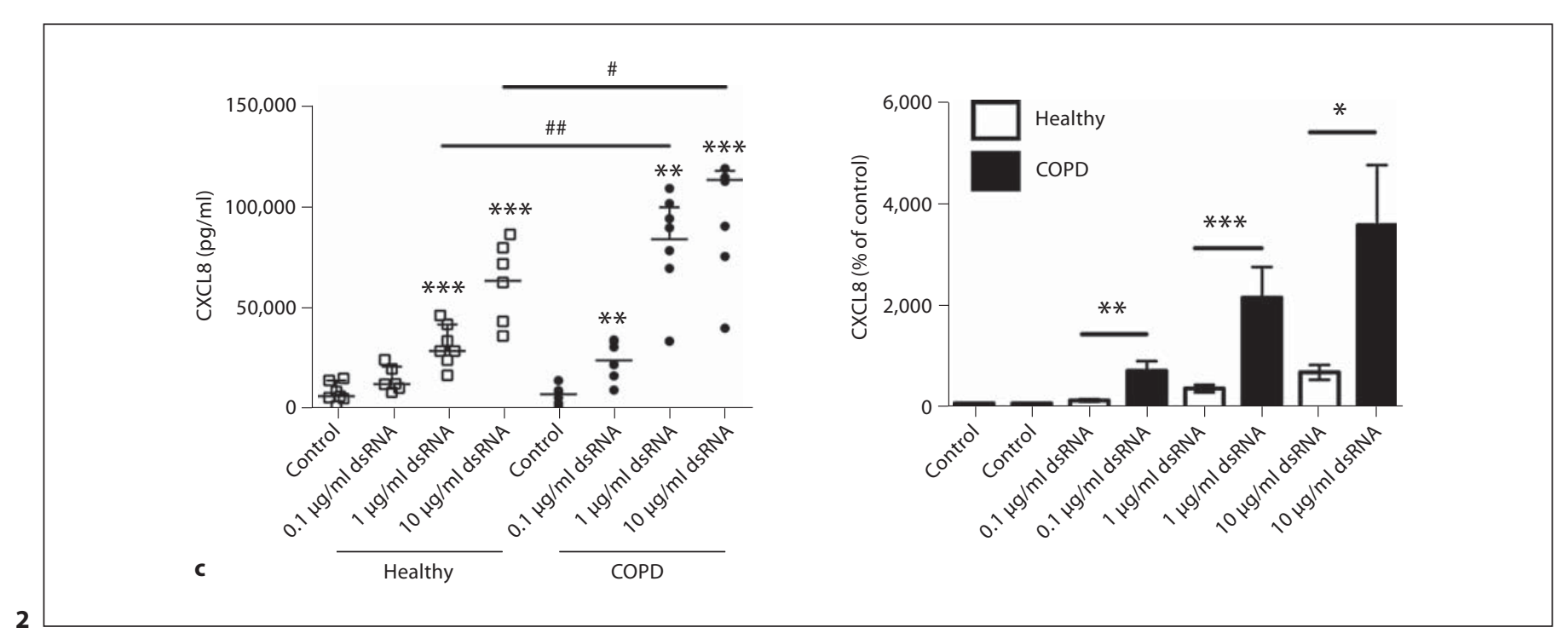


Involvement of TLR3 Signaling in dsRNA-Induced

Overproduction of TSLP, TNF- $\alpha$, and CXCL8:

Inhibition by Chloroquine

TLR3 receptors in epithelial cells are expressed in the endosomal compartment of the cell and need an acidic environment for proper signaling [23]. Chloroquine inhibits endosomal acidification and can thus be used as a tool to indicate involvement of endosomal TLR3 signaling in dsRNA-induced epithelial responses [11]. Induction of TSLP release from COPD-BEC by dsRNA was dose-dependently and completely inhibited by chloroquine (5 and $10 \mu \mathrm{g} / \mathrm{ml}$ ), suggesting that TSLP expression is entirely dependent on TLR3 receptor activation (fig. 3a). Release of TNF- $\alpha$ and CXCL8 in response to dsRNA was also reduced to near control levels by chloroquine in HBEC (fig. 3b, c). In contrast, for COPD-BEC, even at the highest concentration of chloroquine, dsRNA significantly ( $\mathrm{p}<0.01-0.001)$ stimulated TNF- $\alpha$ and CXCL8 release suggesting that other pattern recognition receptors, together with TLR3, are involved in the dsRNA-induced responses (fig. 3b, c).

\section{Effects of dsRNA-LyoVec on Generation of TSLP,}

TNF- $\alpha$, and CXCL8

Since cytosolic RIG-I-like helicases such as RIG-I and MDA5 would not be affected by inhibition of endosome acidification, we further examined the effects of a dsRNA formulation (dsRNA-LyoVec) constructed to be confined to the cytoplasm where RNA helicases are located [22] (see below). In contrast with the effect of dsRNA, dsRNALyoVec $(0.1-1 \mu \mathrm{g} / \mathrm{ml})$ did not increase TSLP gene and protein release from HBEC or COPD-BEC (fig. 4a). However, dsRNA-LyoVec $(0.1-1 \mu \mathrm{g} / \mathrm{ml})$ did increase TNF- $\alpha$ as well as CXCL8 production in COPD-BEC, but had no effect on HBEC (fig. 4b, c). Treating cells with LyoVec alone had no effect on cytokine production (data not shown). The endosomal TLR3 inhibitor chloroquine did

Fig. 2. Effects of dsRNA on 24-hour protein release of TSLP (a), TNF- $\alpha$ (b), and CXCL8 (c) in BEC from patients with severe COPD and healthy individuals. dsRNA induced overproduction of TSLP protein in the COPD group (a). Similarly, TNF- $\alpha$ protein (b) and CXCL8 (c) were overproduced in response to dsRNA in epithelial cells from COPD compared to cells from healthy donors. Each point corresponds to a single individual and data are expressed as medians with IQR. ${ }^{*} \mathrm{p}<0.05,{ }^{* *} \mathrm{p}<0.01,{ }^{* * *} \mathrm{p}<0.001$ vs. control; ${ }^{\#} \mathrm{p}<0.05,{ }^{\# \#} \mathrm{p}<0.01,{ }^{\# \# \#} \mathrm{p}<0.001$ healthy vs. COPD. not reduce the increased production of CXCL8 induced by dsRNA-LyoVec in COPD-BEC, supporting the view that dsRNA-LyoVec is specific to cytosolic RIG-I-like receptors (fig. $4 \mathrm{~d}$ ) and does not interact with other dsRNA pattern recognition receptors such as TLR3.

\section{dsRNA Evokes Dose-Dependent Generation of IFN- $\beta$} Equally in $\mathrm{HBEC}$ and COPD-BEC

Both RV infection and dsRNA stimulation have revealed a deficient antiviral IFN- $\beta$ response in asthmatic BEC compared to HBEC [5]. Therefore, we next investigated induction of IFN- $\beta$ in COPD-BEC challenged with dsRNA. This revealed a clear dose-dependent induction of mRNA expression and release of IFN- $\beta$ protein in COPD-BEC as well as in HBEC (fig. 5). However, there was no significant difference between the IFN- $\beta$ responses of COPD-BEC and HBEC controls ( $p>0.2$ ). IFN- $\beta$ induction by dsRNA was reduced by chloroquine pretreatment, as previously found in asthmatic BECs (fig. 5c); dsRNA-LyoVec also induced IFN- $\beta$ expression (fig. 6a). However, in this case the response was chloroquine insensitive (fig. 6b).

\section{Confirmation of Cytokine Overproduction by \\ Infecting COPD-BEC with RV16}

To determine whether the exaggerated cytokine production in COPD-BEC in response to dsRNA was characteristic of a response to infection, BECs were exposed to RV16 at different MOI. Consistent with the results of dsRNA stimulation, RV16 caused a significant increase in TSLP release only in the COPD-BEC, and there was exaggerated production of CXCL8 and TNF- $\alpha$ in COPDBEC compared to HBEC (fig. 7a-c). Furthermore, as found with the dsRNA, IFN- $\beta$ production was similar in HBEC and COPD-BEC exposed to RV16 (fig. 7d). Cell death was not investigated as a separate read-out in our study. RV16 causes cell death dependent on MOI used. We used a rather low dose of RV16 (1-5 MOI). We already got good responses at 1-2 MOI, a level at which most human epithelial cells survive infection with RV16 [5]. Also the present responses were not much increased at 5 MOI. UV exposure affects the viral nucleic acid resulting in formation of uracil dimers that will prevent the virus from replicating. However, the irradiated virus will still have the capability of binding to the epithelial cells. This alone may cause cell activation. Since UV control data in this study were similar to the effects of culture medium (fig. 7), we conclude that the effects of the RV are dependent on viral replication and thus likely reflect formation of dsRNA molecules. 

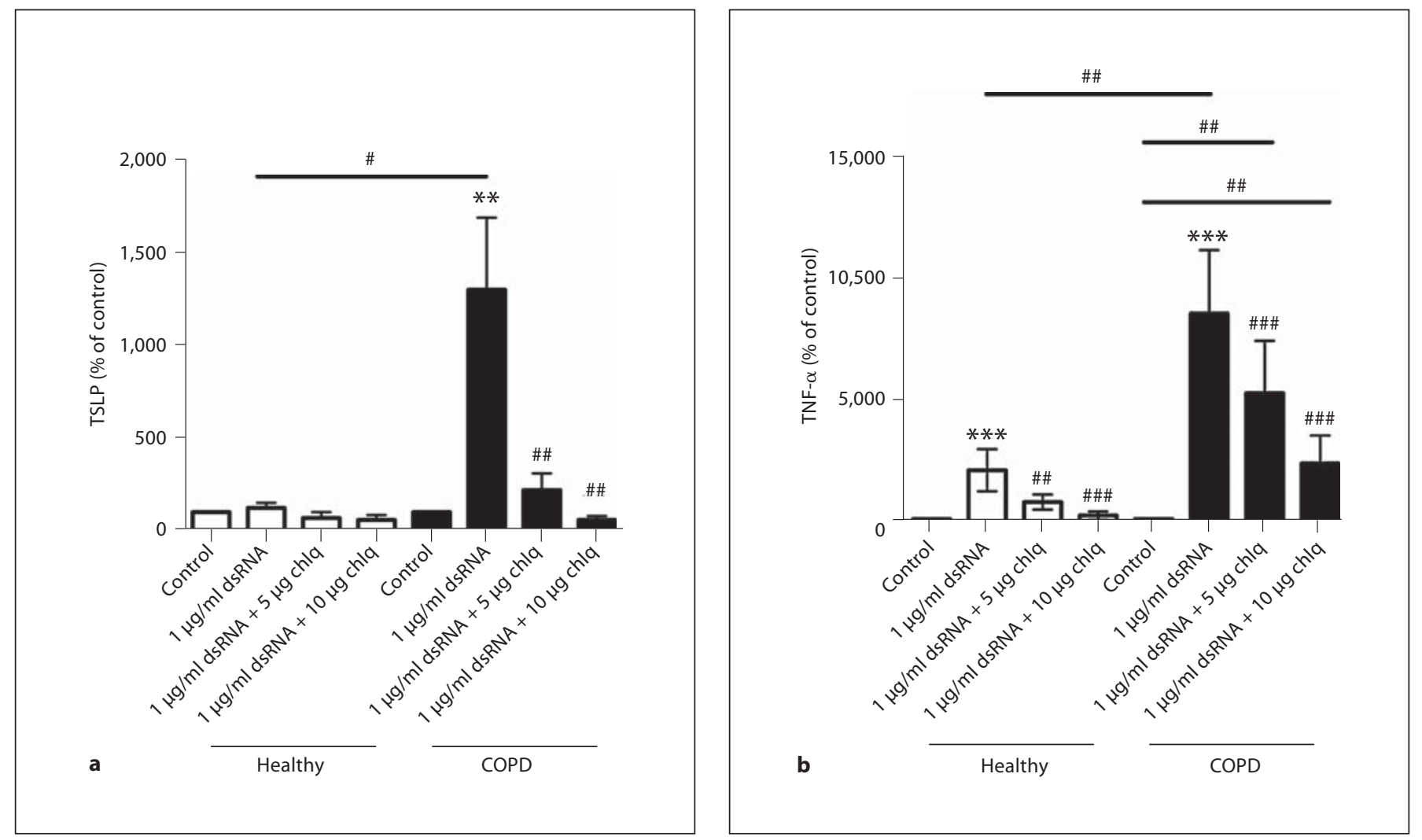

Fig. 3. Effects of chloroquine (endosomal TLR3 inhibitor; chlq) on dsRNA-induced 24-hour cytokine release in COPD and HBEC. TSLP protein release was completely inhibited by chlq treatment (5 and $10 \mu \mathrm{g}$ added to the $1-\mathrm{ml}$ cell culture medium well $1 \mathrm{~h}$ prior to dsRNA) in both the healthy and COPD groups (a). TNF- $\alpha$ protein was dose-dependently reduced by chloroquine, but remained elevated above control especially in COPD cells (b). Similar to TNF- $\alpha$, CXCL8 was incompletely inhibited by chlq (c). Data are expressed as medians with IQR. ${ }^{*} \mathrm{p}<0.05,{ }^{*} \mathrm{p}<0.01$, ${ }^{* * *} \mathrm{p}<0.001$ vs. control; ${ }^{\#} \mathrm{p}<0.05,{ }^{\# \#} \mathrm{p}<0.01,{ }^{\# \# \#} \mathrm{p}<0.001$ healthy vs. COPD. 

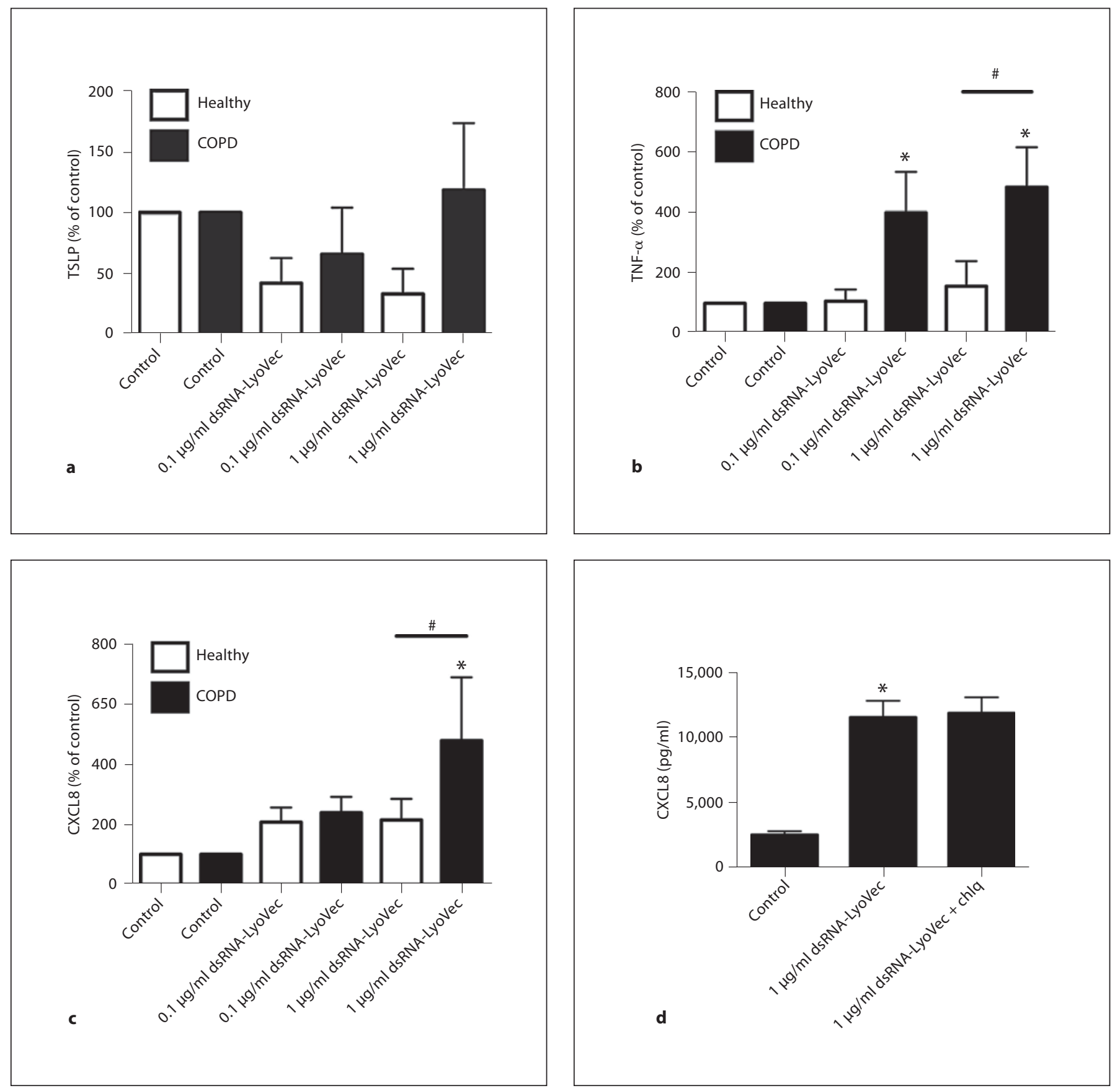

Fig. 4. dsRNA-LyoVec was used for selective stimulation of cytosolic RIG-I-like receptors. TSLP was not induced by dsRNA-LyoVec (a). In contrast, only CXCL8 and TNF- $\alpha$ proteins were significantly produced in response to dsRNA-LyoVec and then only in the COPD group $(\mathbf{b}, \mathbf{c})$. Data expressed as medians with IQR. * $\mathrm{p}<0.05$ vs. control; ${ }^{*} \mathrm{p}<0.05$ healthy vs. COPD. The effect of chloroquine on 24-hour production of CXCL8 (d) induced by dsRNA-LyoVec in COPD-BEC. The endosomal TLR3 inhibitor chloroquine (chlq) $10 \mu \mathrm{g} / \mathrm{ml}$ added $1 \mathrm{~h}$ prior to stimulation with dsRNA-LyoVec was without effect, supporting the view that dsRNA-LyoVec specifically stimulates cytosolic RIG-I-like receptors $(n=3)$. Data expressed as means \pm SEM. ${ }^{*} \mathrm{p}<0.05$ vs. control. 

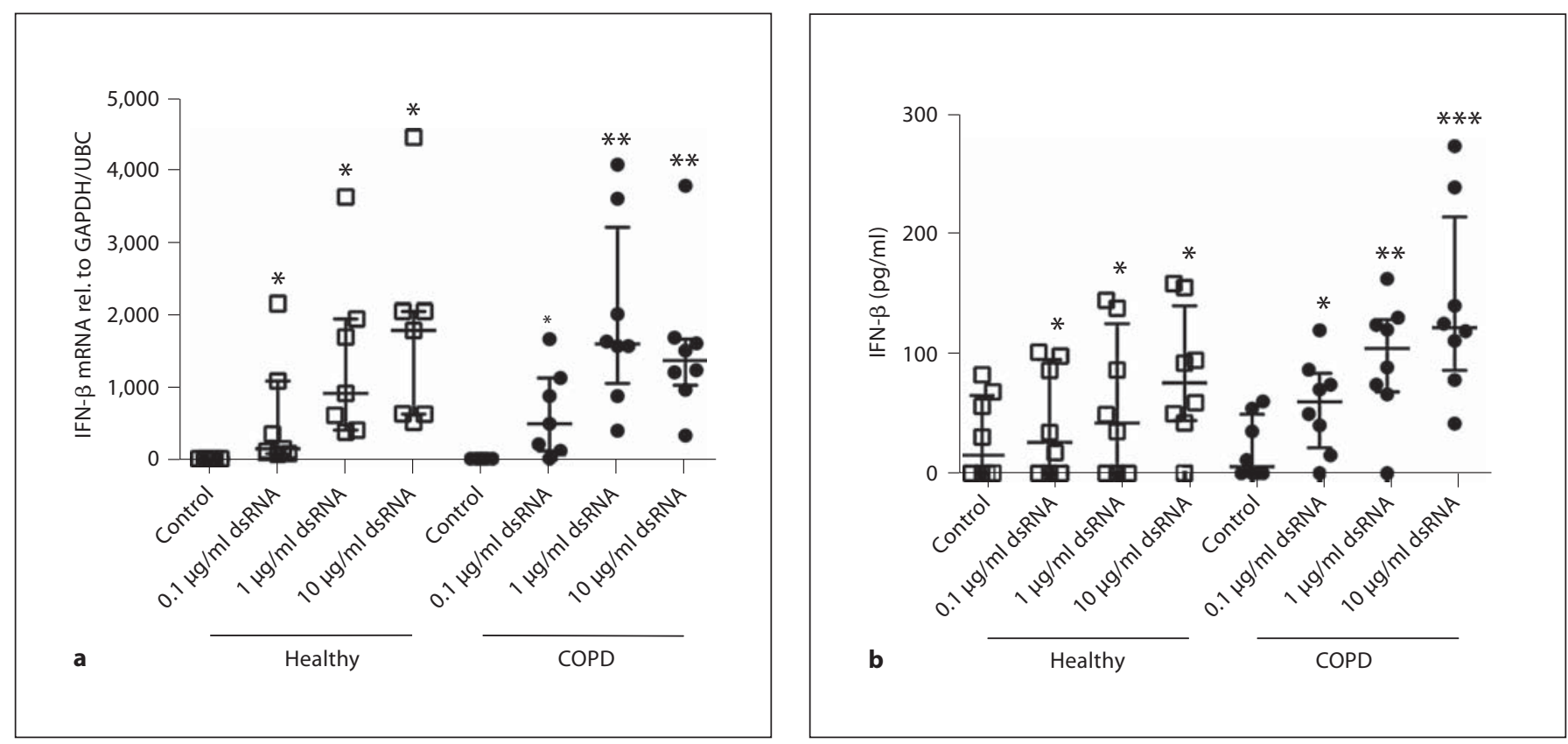

Fig. 5. dsRNA-induced antiviral IFN- $\beta$ mRNA and protein release in COPD and HBEC. IFN- $\beta$ mRNA at $3 \mathrm{~h}$ was significantly induced at all doses of dsRNA and to similar levels in the COPD and healthy groups (a). Similar responses in healthy and COPD tissue were also observed regarding 24 -hour IFN- $\beta$ protein release (b). The IFN- $\beta$ protein release was dependent on TLR3 signaling as chloroquine (chlq) reduced the levels to near control levels (c). Each point corresponds to a single individual, and data are expressed as medians with IQR. ${ }^{*} \mathrm{p}<0.05,{ }^{* *} \mathrm{p}<0.01$, ${ }^{* * *} \mathrm{p}<0.001$ vs. control; ${ }^{*} \mathrm{p}<0.05$ healthy vs. COPD.

\section{Discussion}

BECs are considered a central cell type in the pathogenesis of COPD, and RV infection is a central trigger for exacerbations of this disease. In the present study, we have used three different kinds of stimuli to activate viral pattern recognition receptors in primary COPD-BEC

and HBEC: RV16 and dsRNA stimulating both endosomal TLR3 and cytosolic RIG-I-like helicases and dsRNALyoVec being specific for RIG-I-like helicases. We discovered that COPD-BECs, stimulated with dsRNA or infected with RV16, responded with exaggerated expression and production of the $\mathrm{TH}_{2}$-inducing cytokine TSLP. These data suggest the possibility of involvement of TSLP 

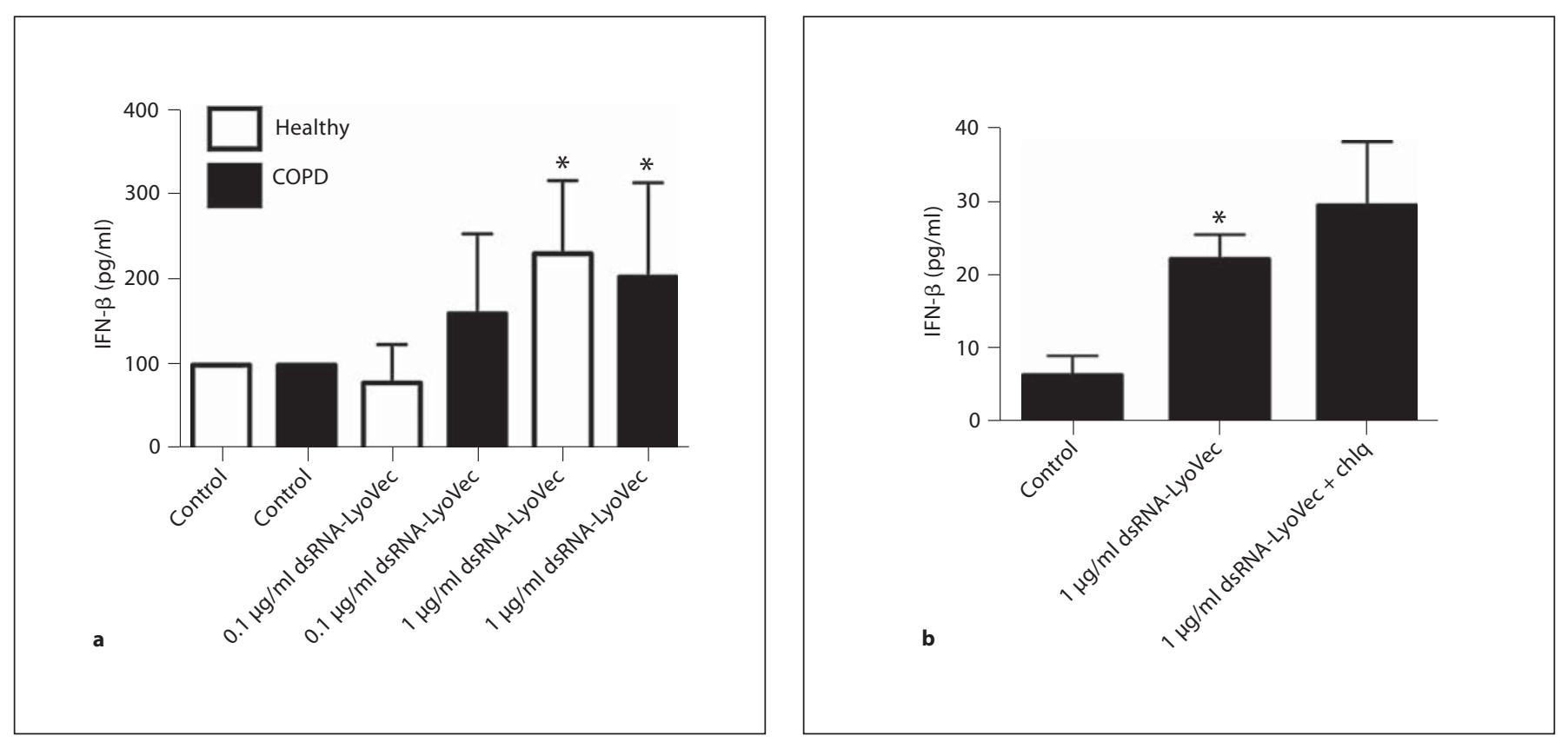

Fig. 6. dsRNA-LyoVec was used for selective stimulation of cytosolic RIG-I like receptors and tested for induction of IFN- $\beta$ protein as in figure 4 . IFN- $\beta$ was induced by dsRNA-LyoVec (a). Data are expressed as median value with interquartile range. ${ }^{*} \mathrm{p}<0.05$ vs. control. Effects of chloroquine on 24 -hour production of IFN- $\beta$ (b) induced by dsRNA-LyoVec in COPD-BEC. The endosomal TLR3 inhibitor chloroquine (chlq) $10 \mu \mathrm{g} / \mathrm{ml}$ added $1 \mathrm{~h}$ prior to stimulation with dsRNA-LyoVec was without effect $(\mathrm{n}=3)$. Data expressed as means \pm SEM. ${ }^{*} \mathrm{p}<0.05$ vs. control.

in viral-induced exacerbations of COPD. We further demonstrated for the first time that all three viral stimuli caused overproduction of TNF- $\alpha$ and CXCL8. The latter two cytokines are already acknowledged as pathogenic cytokines in COPD [25]. Our novel data strengthen the possibility that they are involved in exacerbations of this disease. Antiviral IFN- $\beta$ production was also increased by all three viral stimuli, but to the same extent as in COPD-BEC and HBEC. The present data together with our previous findings $[5,11]$ reveal several differences between asthmatic and COPD epithelial cell innate antiviral responses. Thus, it was only in COPD epithelial cells that viral stimulation overproduced TNF- $\alpha$ and CXCL8 (this study), whereas the production of these cytokines in asthmatic cells did not differ from normal healthy cells [11]. Also, the present diseased COPD epithelial cells responded normally to viral stimuli as regards IFN- $\beta$ production, thus differing from the deficient generation of IFN- $\beta$ in epithelium from asthmatic donors [5]. Against these differences the similar overproduction of TSLP stands out. The present demonstration of TSLP overproduction in COPD cells make it of interest to consider po- tential roles of this cytokine in exacerbations and development of severe COPD.

In this study, the significant differences in epithelial cell responses to viral stimuli between COPD and healthy donors were maintained for at least three passages. It is thus possible that our data may reflect the responsiveness of the bronchial epithelium in situ in COPD. However, translation from isolated cells in culture to in vivo, where cells dwell in a highly complex and dynamic milieu, must remain speculative until proven by direct experiments in patients. In this study, the epithelial cells from COPD donors did not differ from control cells regarding baseline expression of cytokines. Moreover, dsRNA-induced TSLP mRNA and protein did not differ between BEC from smokers and non-smoking healthy donors. These observations suggest that the viral stimulus-induced overproduction is a feature of the epithelial phenotype in severe COPD disease rather than merely reflecting effects of historical exposure to cigarette smoke. Both viral infection and dsRNA caused overproduction of TSLP, TNF- $\alpha$, and CXCL8. However, exposure to UV-inactivated virus was ineffective, suggesting that the increased cy- 

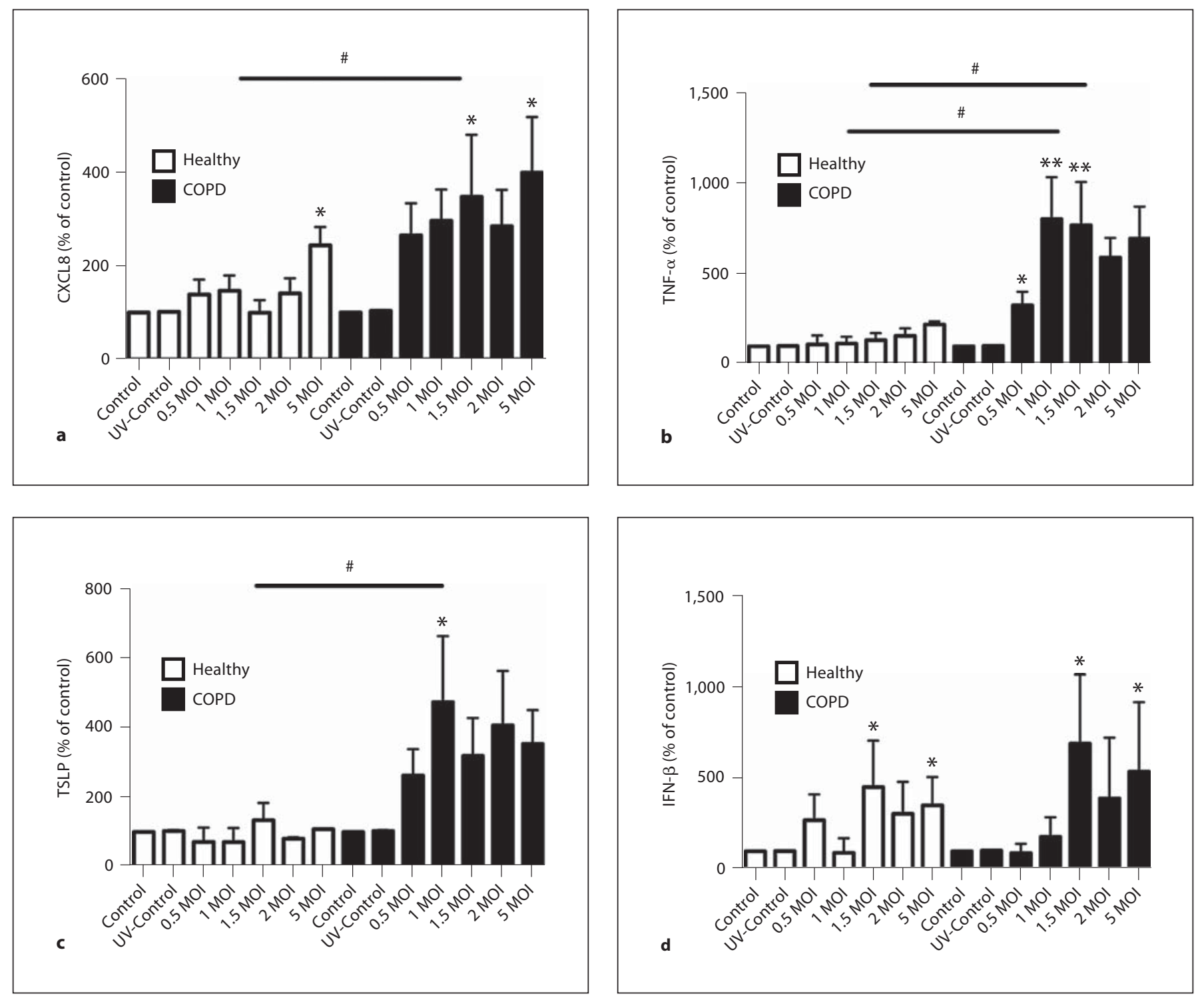

Fig. 7. RV16-induced effects on epithelial cells obtained from healthy and COPD donors. Confirming the exaggerated cytokine production in COPD cells in response to dsRNA and dsRNA-LyoVec, inoculation with RV16 at different MOI caused significant overproduction of CXCL8 (a), TNF- $\alpha$ (b), and TSLP (c) in COPD cells compared to marginal effects in healthy cells. The lack of any induced overproduction of IFN- $\beta$ (d) was also confirmed by the similar IFN- $\beta$ production in healthy and COPD cells exposed to RV16. Data are expressed as medians with IQR. ${ }^{*} \mathrm{p}<0.05,{ }^{* *} \mathrm{p}<0.01$ vs. control; ${ }^{*} \mathrm{p}<0.05$ healthy vs. COPD.

tokine production in COPD-BEC is dependent on viral replication. Together these data support the relevance of dsRNA-induced responses for events occurring during RV infection and replication in BEC. Generally, dsRNA produced much greater effects than the different levels of RV exposure in this study did. This finding likely reflects, at least in part, the limited number of epithelial cells that actually will become infected by the virus [26].
To activate the epithelial cells through endosomal TLR3, the added synthetic dsRNA needs to be internalized, possibly by clathrin-mediated endocytosis [27, 28]. Chloroquine is known to inhibit endosomal acidification [23], and thus it inhibits endosomal TLR3 responses [11, 28]. In the concentrations used in this study, chloroquine is non-toxic to human BEC [11]. Its dose-dependent inhibitory effects together with its lack of effects on dsRNA- 
LyoVec-induced cytokines support the specificity of chloroquine's endosomal action in this study. Hence, the observation of complete inhibition of dsRNA-induced generation of TSLP, even in the over-responsive COPD$\mathrm{BEC}$, suggests that endosomal TLR3 mediates this effect. Both the overproduction of TSLP in COPD-BEC and its inhibition by incubation with chloroquine agree with our previous observations in BEC obtained from asthmatic donors [11], although the overproduction appears to be greater in COPD. The role of TLR3 in dsRNA-induced TSLP expression has previously been suggested by Kato et al. [9] who reported that dsRNA-induced TSLP in healthy epithelial cells was halved by transfection with small interfering RNA against TLR3. The transcription factor NFkB mediates cytokine gene activation downstream of TLR3 signaling. Drugs that inhibit NFkB by stabilizing its binding to IkB have also been shown to be effective inhibitors of TSLP generation in dsRNA-stimulated BEC from healthy and diseased donors [29]. Additionally, such drugs have produced a less desirable inhibition of the antiviral IFN- $\beta$ in these BEC [Uller et al. unpubl. obs.]. The present findings do not suggest possibilities of separating antiTSLP and anti-IFN- $\beta$ effects since chloroquine reduced IFN- $\beta$ along with the inhibition of TSLP.

Compared to its effect on TSLP generation, chloroquine was a less effective inhibitor of CXCL8 and TNF- $\alpha$ expression, suggesting that non-endosomal dsRNA-responsive elements were involved in the generation of these cytokines. It is well established that dsRNA and RV are not only recognized by TLR 3 but also by cytosolic helicases (RIG-I, MDA5) [22,28]. To elucidate involvement of cytosolic RIG-like helicases, we used a special dsRNA formulation by which poly I:C is formulated with the transfection agent LyoVec (dsRNA-LyoVec). This agonist does not affect endosomal TLR3, but is confined to the cytoplasm where the RIG-I-like helicases are located [22]. Importantly, this study demonstrated that dsRNALyoVec induced no expression or production of TSLP. By contrast, dsRNA-LyoVec effectively induced generation of TNF- $\alpha$ and CXCL8 additionally revealing that the stimulation of cytosolic RIG-I and/or MDA5 induced production of these two cytokines only in COPD-BEC. Future studies are warranted to further explore mechanisms by which epithelial cy tosolic helicases have gained an abnormal responsiveness in COPD compared to HBEC. Taken together, the inhibitory data obtained with chloroquine alongside the lack of stimulatory effects of dsRNA-LyoVec are mutually supportive of major involvement of TLR 3 in the generation of TSLP in virally stimulated COPD-BEC. Similarly, the present data jointly in- dicate that cytosolic RIG-I-like helicases, together with endosomal TLR3, are involved in the virally induced production of CXCL8 and TNF- $\alpha$, especially in COPD-BEC. The partly distinct mechanisms suggest the possibility of finding drugs that preferentially attenuate the generation of TSLP without inhibiting CXCL8 and TNF- $\alpha$. Although there is interest in developing drugs that inhibit CXCL8 and TNF- $\alpha$, both these cytokines may be important not only in COPD pathogenesis but also in neutrophilic innate host defense in the lung. Of note in this context, anti-TNF- $\alpha$ treatment has been disappointing due to its side effects and lack of clinical efficacy in COPD, but effects specifically on RV-induced exacerbations of COPD have not been studied as yet [30]. Involvement of RIG-I-like helicases in IFN- $\beta$ generation, in addition to TLR3, has been suggested [31]. Here, we demonstrate that dsRNA-LyoVec evoked a small but significant production of IFN- $\beta$ in COPD-BEC (as well as HBEC) that was not reduced by chloroquine, suggesting that cytosolic RIG-Ilike helicases in part may mediate viral-induced IFN- $\beta$ in COPD-BEC.

The present data on overproduction of CXCL8 in epithelial cells from COPD donors may agree in part with findings by Schneider et al. [32] who reported somewhat higher absolute supernatant concentrations of CXCL8 in RV-infected epithelial cells from COPD individuals compared to normal cells from non-smoking subjects. However, differing from this study, where UV-inactivated RV was without effect, these authors observed a similar response also to their control UV-inactivated virus exposure. Distinct from the present data, they further reported that the COPD cells had an elevated baseline production of CXCL8 over normal cells [32]. These differences between their study and the present data remain unexplained, but may relate to the prolonged culture method and the air-liquid interface conditions employed by Schneider et al. [32]. Air-liquid-interface-grown epithelium eventually differentiates to multilayered epithelial cells which include ciliated cells and mucus-producing goblet cells. Such cultures obtained from patients with COPD and asthma have been shown to include a higher proportion of goblet cells compared to cultures from healthy controls. Surprisingly, in their test system of COPD cells, Schneider et al. [32] could not even detect IFN- $\beta$ protein in the supernatant despite a higher IFN- $\beta$ mRNA. In the present study, the dsRNA-induced increase in TSLP mRNA in control cells was also poorly translated into TSLP protein. The detailed mechanisms involved in such discrepancies are not known. There are several steps at which host protein synthesis could be altered in re- 
sponse to viral stimulation [32]. The examples quoted here indicate the importance of determining actual protein synthesis-release since merely epithelial mRNA changes may not cause an appreciable change in the protein microenvironment that is created by epithelial cells.

Papi et al. [2] observed that those COPD patients whose exacerbations were associated with viral infection also developed an airway eosinophilia possibly reflecting $\mathrm{TH}_{2}$-type inflammation. Furthermore, several groups have now demonstrated that exacerbations of COPD are associated with a marked development of $\mathrm{TH}_{2}$ type of lymphocytes $[14,15]$. Further support for a $\mathrm{TH}_{2}$-type inflammation is the observation of high airway levels of IL-4 in exacerbating COPD disease [18]. Original observations in mouse models suggest the possibility of involvement of prostaglandin $\mathrm{D}_{2}$ and the $\mathrm{CRTH} 2$ receptors in development of $\mathrm{TH}_{2}$-type airway inflammation [33] and that dsRNA uses this pathway to augment allergic airway inflammation [34]. However, the $\mathrm{TH}_{2}$-like mechanisms involved in exacerbations of COPD have not been fully assessed. The present data suggest that epithelialderived TSLP can be involved in viral-induced exacerbations of severe COPD. The known actions of TSLP on human immune cells support this hypothesis. Directly, or indirectly through priming of dendritic cells, TSLP thus expands CD4+ and CD8+ T cells into effector cells producing $\mathrm{TH}_{2}$ cytokines but also $\mathrm{TH}_{1}$ cytokines such as TNF- $\alpha$ and IFN- $\gamma[7,35]$. Although unexpected, the finding by Ying et al. [36] that the TSLP gene was overexpressed in bronchial epithelium in biopsies not only from asthmatics but also from patients with COPD is of significant interest. Indeed, there is increasing realization that asthma and COPD exhibit many similarities especially at the severe end of these diseases [37]. The similarities include features of genetic background, chronic immunopathological mechanisms, exacerbating factors, and effects of treatment. Frequent exacerbations may be a causative factor in development of increasingly severe COPD [19]. Speculatively then, frequent viral induced generation of TSLP in COPD airways could involve this cytokine in multiple aspects of development of this disease. Thus, through its effects on B cells [38] and on differentiation of TH17 cells [39] TSLP may promote development of autoimmunity, a potential component of COPD that recently has become quite topical [40]. Through other effects than the epithelial generation of TSLP, a primary TLR3 stimulation could also favour development of autoimmunity [28].

In conclusion, the present novel data indicate that endosomal chloroquine-sensitive TLR3 stimulation induced by dsRNA, as well as by RV16, triggers exaggerated expression and release of TSLP in COPD-BEC. Furthermore, we demonstrate for the first time dsRNA- and RV16-induced overproduction of TNF- $\alpha$ and CXCL8 in COPD-BEC. Data obtained by intervention with chloroquine and by stimulation with a cytosol-restricted dsRNA stimulus jointly suggest that overproduction of TNF- $\alpha$ and CXCL8 involves both endosomal TLR3 and cytosolic RIG-I-like helicases. Future work on the expression of endosomal TLR3 as well as the RIG-like helicases in COPD-BEC is warranted to shed further light on mechanisms of cytokine overproduction in these cells. In contrast to the other cytokines, IFN- $\beta$, involving both the endosomal and cytosolic viral sensing elements, is induced to the same extent in COPD-BEC as in HBEC by the viral stimuli in this study. We suggest that RV-induced epithelial TSLP may contribute to pathogenic effects occurring at exacerbations of COPD and, hence, that TSLP-generating mechanisms could be potential targets for future treatments of this disease.

\section{References}

1 Mallia P, Johnston SL: How viral infections cause exacerbation of airway diseases. Chest 2006;130:1203-1210.

-2 Papi A, Bellettato CM, Braccioni F, Romagnoli M, Casolari P, Caramori G, Fabbri LM, Johnston SL: Infections and airway inflammation in chronic obstructive pulmonary disease severe exacerbations. Am J Respir Crit Care Med 2006;173:1114-1121.

-3 Papadopoulos NG, Bates PJ, Bardin PG, Papi A, Leir SH, Fraenkel DJ, Meyer J, Lackie PM, Sanderson G, Holgate ST, Johnston SL: Rhinoviruses infect the lower airways. J Infect Dis 2000;181:1875-1884.
4 Gern JE, Galagan DM, Jarjour NN, Dick EC, Busse WW: Detection of rhinovirus RNA in lower airway cells during experimentally induced infection. Am J Respir Crit Care Med 1997;155:1159-1161.

5 Wark PA, Johnston SL, Bucchieri F, Powell R, Puddicombe S, Laza-Stanca V, Holgate ST, Davies DE: Asthmatic bronchial epithelial cells have a deficient innate immune response to infection with rhinovirus. J Exp Med 2005;201:937-947.

-6 Holgate ST: The epithelium takes centre stage in asthma and atopic dermatitis. Trends Immunol 2007;28:248-251.
7 He R, Geha RS: Thymic stromal lymphopoietin. Ann N Y Acad Sci 2010;1183:13-24.

8 Zhou B, Comeau MR, De Smedt T, Liggitt HD, Dahl ME, Lewis DB, Gyarmati D, Aye T, Campbell DJ, Ziegler SF: Thymic stromal lymphopoietin as a key initiator of allergic airway inflammation in mice. Nat Immunol 2005;6:1047-1053.

-9 Kato A, Favoreto S Jr, Avila PC, Schleimer RP: Tlr3- and th2 cytokine-dependent production of thymic stromal lymphopoietin in human airway epithelial cells. J Immunol 2007;179:1080-1087. 
10 Gern JE, French DA, Grindle KA, Brockman-Schneider RA, Konno S, Busse WW: Double-stranded RNA induces the synthesis of specific chemokines by bronchial epithelial cells. Am J Respir Cell Mol Biol 2003;28: 731-737.

-11 Uller L, Leino M, Bedke N, Sammut D, Green B, Lau L, Howarth PH, Holgate ST, Davies DE: Double-stranded RNA induces disproportionate expression of thymic stromal lymphopoietin versus interferon-beta in bronchial epithelial cells from donors with asthma. Thorax 2010;65:626-632.

-12 Wang Q, Nagarkar DR, Bowman ER, Schneider D, Gosangi B, Lei J, Zhao Y, McHenry CL, Burgens RV, Miller DJ, Sajjan U, Hershenson MB: Role of double-stranded RNA pattern recognition receptors in rhinovirus-induced airway epithelial cell responses. J Immunol 2009;183:6989-6997.

13 Cavassani KA, Ishii M, Wen H, Schaller MA, Lincoln PM, Lukacs NW, Hogaboam CM, Kunkel SL: TLR3 is an endogenous sensor of tissue necrosis during acute inflammatory events. J Exp Med 2008;205:2609-2621.

$\checkmark 14$ Makris D, Lazarou S, Alexandrakis M, Kourelis TV, Tzanakis N, Kyriakou D, Gourgoulianis KI: Tc2 response at the onset of COPD exacerbations. Chest 2008; 134:483488.

-15 Barcelo B, Pons J, Fuster A, Sauleda J, Noguera A, Ferrer JM, Agusti AG: Intracellular cytokine profile of $\mathrm{T}$ lymphocytes in patients with chronic obstructive pulmonary disease. Clin Exp Immunol 2006; 145: 474-479.

-16 Barczyk A, Pierzchala W, Kon OM, Cosio B, Adcock IM, Barnes PJ: Cytokine production by bronchoalveolar lavage $\mathrm{T}$ lymphocytes in chronic obstructive pulmonary disease. J Allergy Clin Immunol 2006;117:1484-1492.

17 Mattoli S, Kleimberg J, Stacey MA, Bellini A, Sun G, Marini M: The role of CD8+ Th2 lymphocytes in the development of smoking-related lung damage. Biochem Biophys Res Commun 1997;239:146-149.

- 18 Singh M, Lee SH, Porter P, Xu C, Ohno A, Atmar RL, Greenberg SB, Bandi V, Gern J, Amineva S, Aminev A, Skern T, Smithwick P, Perusich S, Barrow N, Roberts L, Corry DB, Kheradmand F: Human rhinovirus proteinase $2 \mathrm{a}$ induces Th1 and Th2 immunity in patients with chronic obstructive pulmonary disease. J Allergy Clin Immunol 2010; 125:1369-1378.e2.

-19 Hurst JR, Vestbo J, Anzueto A, Locantore N, Mullerova H, Tal-Singer R, Miller B, Lomas DA, Agusti A, Macnee W, Calverley P, Rennard S, Wouters EF, Wedzicha JA: Susceptibility to exacerbation in chronic obstructive pulmonary disease. N Engl J Med 2010;363: $1128-1138$.
20 Keatings VM, Collins PD, Scott DM, Barnes PJ: Differences in interleukin-8 and tumor necrosis factor-alpha in induced sputum from patients with chronic obstructive pulmonary disease or asthma. Am J Respir Crit Care Med 1996;153:530-534.

21 Aaron SD, Angel JB, Lunau M, Wright K, Fex C, Le Saux N, Dales RE: Granulocyte inflammatory markers and airway infection during acute exacerbation of chronic obstructive pulmonary disease. Am J Respir Crit Care Med 2001;163:349-355.

22 Yoneyama M, Fujita T: Function of RIG-Ilike receptors in antiviral innate immunity. J Biol Chem 2007;282:15315-15318.

23 De Bouteiller O, Merck E, Hasan UA, Hubac S, Benguigui B, Trinchieri G, Bates EE, Caux C: Recognition of double-stranded RNA by human toll-like receptor 3 and downstream receptor signaling requires multimerization and an acidic pH. J Biol Chem 2005;280: 38133-38145.

24 Lordan JL, Bucchieri F, Richter A, Konstantinidis A, Holloway JW, Thornber M, Puddicombe SM, Buchanan D, Wilson SJ, Djukanovic R, Holgate ST, Davies DE: Cooperative effects of Th2 cytokines and allergen on normal and asthmatic bronchial epithelial cells. J Immunol 2002;169:407-414.

25 Wedzicha JA, Seemungal TA: COPD exacerbations: defining their cause and prevention. Lancet 2007;370:786-796.

26 Wos M, Sanak M, Soja J, Olechnowicz H, Busse WW, Szczeklik A: The presence of rhinovirus in lower airways of patients with bronchial asthma. Am J Respir Crit Care Med 2008;177:1082-1089.

27 Itoh K, Watanabe A, Funami K, Seya T, Matsumoto M: The clathrin-mediated endocytic pathway participates in dsRNA-induced IFN-beta production. J Immunol 2008; 181 : 5522-5529.

28 Vercammen E, Staal J, Beyaert R: Sensing of viral infection and activation of innate immunity by toll-like receptor 3 . Clin Microbiol Rev 2008;21:13-25.

29 Brandelius A, Yudina Y, Calven J, Bjermer L, Andersson M, Persson C, Uller L: DsRNAinduced expression of thymic stromal lymphopoietin (TSLP) in asthmatic epithelial cells is inhibited by a small airway relaxant. Pulm Pharmacol Ther 2010;24:59-66.

-30 Barnes PJ: The cytokine network in asthma and chronic obstructive pulmonary disease. J Clin Invest 2008;118:3546-3556.
1 Slater L, Bartlett NW, Haas JJ, Zhu J, Message SD, Walton RP, Sykes A, Dahdaleh S, Clarke DL, Belvisi MG, Kon OM, Fujita T, Jeffery PK, Johnston SL, Edwards MR: Co-ordinated role of TLR3, RIG-I and MDA5 in the innate response to rhinovirus in bronchial epithelium. PLoS Pathog 2010;6:e1001178.

- 32 Schneider D, Ganesan S, Comstock AT, Meldrum CA, Mahidhara R, Goldsmith AM, Curtis JL, Martinez FJ, Hershenson MB, Sajjan U: Increased cytokine response of rhinovirus-infected airway epithelial cells in chronic obstructive pulmonary disease. Am J Respir Crit Care Med 2010;182:332-340.

-33 Uller L, Mathiesen JM, Alenmyr L, Korsgren M, Ulven T, Hogberg T, Andersson G, Persson CG, Kostenis E: Antagonism of the prostaglandin $\mathrm{D}_{2}$ receptor CRTH2 attenuates asthma pathology in mouse eosinophilic airway inflammation. Respir Res 2007;8:16.

34 Shiraishi Y, Asano K, Niimi K, Fukunaga K, Wakaki M, Kagyo J, Takihara T, Ueda S, Nakajima T, Oguma T, Suzuki Y, Shiomi T, Sayama K, Kagawa S, Ikeda E, Hirai H, Nagata $\mathrm{K}$, Nakamura $\mathrm{M}$, Miyasho $\mathrm{T}$, Ishizaka A: Cyclooxygenase-2/prostaglandin $\mathrm{D}_{2} /$ CRTH2 pathway mediates double-stranded RNA-induced enhancement of allergic airway inflammation. J Immunol 2008; 180 : 541-549.

35 Liu YJ: Thymic stromal lymphopoietin: master switch for allergic inflammation. J Exp Med 2006;203:269-273.

36 Ying S, O’Connor B, Ratoff J, Meng Q, Fang C, Cousins D, Zhang G, Gu S, Gao Z, Shamji B, Edwards MJ, Lee TH, Corrigan CJ: Expression and cellular provenance of thymic stromal lymphopoietin and chemokines in patients with severe asthma and chronic obstructive pulmonary disease. J Immunol 2008;181:2790-2798.

37 Postma DS, Boezen HM: Rationale for the Dutch hypothesis: allergy and airway hyperresponsiveness as genetic factors and their interaction with environment in the development of asthma and COPD. Chest 2004; 126:96S-104S, discussion 159S-161S

38 Allman D, Northrup D: Giving B cell tolerance the 'TSLiP'. Nat Immunol 2007;8:481483.

-39 Tanaka J, Watanabe N, Kido M, Saga K, Akamatsu T, Nishio A, Chiba T: Human TSLP and TLR3 ligands promote differentiation of Th17 cells with a central memory phenotype under Th2-polarizing conditions. Clin Exp Allergy 2009;39:89-100.

40 Duncan SR: What is autoimmunity and why is it likely to be important in chronic lung disease? Am J Respir Crit Care Med 2010; 181:4-5. 